\title{
The Molecular Basis of Hereditary Complement Factor I Deficiency
}

\author{
Timothy J. Vyse, ${ }^{\star}$ Bernard J. Morley, ${ }^{*}$ István Bartók, ${ }^{*}$ Efstathios L. Theodoridis, ${ }^{*}$ Kevin A. Davies, ${ }^{\star}$ A. David B. Webster, ${ }^{\ddagger}$ \\ and Mark J. Walport * \\ *Rheumatology Unit, Department of Medicine, RPMS, Hammersmith Hospital, London W12 0NN, United Kingdom; and ${ }^{\ddagger}$ Royal Free \\ Hospital, London NW3, United Kingdom
}

\begin{abstract}
The molecular basis of hereditary complement factor I deficiency is described in two pedigrees. In one pedigree, there were two factor I-deficient siblings, one of whom was asymptomatic and the other suffered from recurrent pyogenic infections. Their factor I mRNA was analyzed by reverse transcription of fibroblast RNA followed by amplification using the polymerase chain reaction. Both siblings were homozygous for the same transversion (adenine to thymine) at nucleotide 1282 in the cDNA. This mutation causes histidine- 400 to be replaced by leucine. The altered histidine is a semi-conserved residue within the serine proteinase family, although no function has been ascribed to it. The proband of the second pedigree studied was found to be a compound heterozygote. One allele had the same mutation as the first family, the second allele had a donor splice site mutation that resulted in the deletion of the mRNA encoded in the fifth exon (a low-density lipoprotein receptor domain) from its transcript. (J. Clin. Invest. 1996. 97:925-933.) Key words: complement - factor I - mutation - genetics - immunodeficiency
\end{abstract}

\section{Introduction}

Human complement factor $\mathrm{I}(\mathrm{FI})^{1}$ is a serine proteinase that acts in the regulation of the complement cascade. Hereditary deficiency of FI has been reported in 23 individuals from 19 different pedigrees (1). It is associated with a propensity to pyogenic infection and follows an autosomal recessive pattern of inheritance.

FI is a plasma glycoprotein that circulates in an active form at a concentration of $35 \mu \mathrm{g} / \mathrm{ml}$. Its relative molecular mass $\left(M_{\mathrm{r}}\right)$ is estimated to be 88,000 , and it is composed of two disulfidelinked polypeptide chains $\left(M_{\mathrm{r}} 50,000\right.$ and 38,000$)$. The protein is synthesized as a single chain precursor of 565 amino acids,

Address correspondence to Mark J. Walport, Rheumatology Unit, Department of Medicine, RPMS, Hammersmith Hospital, Du Cane Road, London W12 0NN, UK. Phone: 181740 3276; FAX: 181743 3109. Timothy J. Vyse's current address is Division of Basic Sciences, National Jewish Center for Immunology and Respiratory Medicine, 1400 Jackson Street, Denver, CO 80206.

Received for publication 19 September 1995 and accepted in revised form 28 November 1995.

1. Abbreviation used in this paper: FI, factor I.

J. Clin. Invest.

(C) The American Society for Clinical Investigation, Inc. 0021-9738/96/02/0925/09 \$2.00

Volume 97, Number 4, February 1996, 925-933 predominantly in the liver (2). Four basic amino acids are then excised from the precursor prior to secretion of the heterodimer. FI synthesis has also been demonstrated in vitro by primary monocyte cultures (3), endothelial cells (4), and by the Raji B cell line (5).

The cDNA structure of FI has been published $(6,7)$ and more recently, the genomic organization determined (8). Like many of the complement proteins, FI has a modular structure. The heavy chain contains two low-density lipoprotein receptor (LDLr) domains, a CD5 domain, and a module found only in FI and complement proteins C6 and C7. The FI gene is located on chromosome 4q25 (9) and spans $63 \mathrm{~kb}$. It comprises $13 \mathrm{ex}-$ ons and there is a strong correlation between the exonic organization of the gene and the modular structure of the protein (8). The light chain of FI, which is the serine proteinase region of the molecule, is encoded in five exons. The genomic organization of the enzymic part of FI is similar to that of trypsin. The gene structure is unusual in that the first exon is small, 86 $\mathrm{bp}$, and it is separated from the rest of the gene by a large first intron of $36 \mathrm{~kb}$.

FI cleaves the $\alpha^{\prime}$ chains of $\mathrm{C} 4 \mathrm{~b}$ and $\mathrm{C} 3 \mathrm{~b}$ and thereby is involved in the regulation of both the classical and alternative complement pathways. The function of FI is dependent on various cofactors; the cleavage of $\mathrm{C} 4 \mathrm{~b}$ requires $\mathrm{C} 4$-binding protein (10), and the cleavage of $\mathrm{C} 3 \mathrm{~b}$ is dependent on complement factor $\mathrm{H}$ (11). By its action on $\mathrm{C} 3 \mathrm{~b}$, FI impedes the formation of the alternative pathway $\mathrm{C} 3$ convertase $(\mathrm{C} 3 \mathrm{bBb})$. Thus FI has an important role in inhibiting the amplification loop of the alternative pathway which generates C3 convertase from C3b. In hereditary deficiency of FI, the alternative pathway is not regulated, so there is consumptive depletion of C3. In addition, patients with FI deficiency have consumptive loss of factor B and reduced levels of factor $\mathrm{H}$ (reviewed in reference 1). Indeed, it was the investigation of the physiology of the complement system in the first reported case of FI deficiency (12-15) that generated the early evidence for the existence of the alternative pathway amplification loop (16).

The clinical manifestations of FI deficiency are similar to those of hereditary C3 deficiency, the most common feature being recurrent pyogenic infections, which reflects the role of C3 as an opsonin. The infections usually begin in early childhood, their median age of onset in FI deficiency is 17 mo. There is also an increased susceptibility to Neisseria meningitidis infection. Patients with FI deficiency may also have "immune complex" type illness. There are three such examples reported $(1,17,18)$ in which a multisystem vasculitic illness occurred, which in one case was fatal (17). There have been two reports of asymptomatic individuals with complete FI deficiency $(1,19)$. In both instances they were identified as members of a pedigree in which there was a symptomatic case. One of these asymptomatic cases (1) and her younger brother, who had recurrent infections, belong to the first family studied in this paper. 
The molecular pathology of FI deficiency has not previously been described. In this paper the molecular basis of FI deficiency in two pedigrees is analyzed.

\section{Methods}

Patients. Two families in which there was an inherited deficiency of FI were studied. In family 1, the proband presented at the age of 18 mo with Staphylococcus epidermidis septic arthritis of the left shoulder. He subsequently had recurrent sinusitis and otitis media and at the age of $13 \mathrm{yr}$ a $N$. meningitidis meningitis. The patient had a sister who is five years older. She has no history of increased susceptibility to pyogenic infections. The history of this patient and his sister and their complement investigations are described in reference 1. Briefly, they both had no detectable circulating FI or factor B, and a very low complement C3 level (most of which was in the form of C3b) measured by radial immunodiffusion using ovine polyclonal antisera (The Binding Site, Birmingham, U.K.). In addition, no detectable alternative pathway activity was detected when determined by hemolytic assay with guinea pig erythrocytes in the presence of $7 \mu \mathrm{M} \mathrm{MgCl}_{2}$ and $10 \mathrm{mM}$ ethyleneglycol tetraacetic acid (20). Both parents, who were well and had no history to suggest a susceptibility to infection, had $\sim$ $50 \%$ of normal circulating FI, but factor B and C3 concentrations were within normal limits. The parents were both from western Scotland, there was no history of consanguinity. In family 2 , the proband was the second case of FI deficiency to be reported (21). She presented with a history of recurrent infections that began at the age of four months with bacterial meningitis (Streptococcus pneumoniae) and otitis media. Between the ages of 7 and 15 years she had four further episodes of meningitis. The causative agent was identified on two occasions and found to be $N$. meningitidis. She had no detectable circulating FI and low C3 (30\% normal human serum). Her mother had $\sim 50 \%$ normal circulating FI. Her father was not available for study. There was no known relation between family 1 and family 2 .

Southern blotting. Genomic DNA was extracted from whole blood as described (22). A total of $10 \mu \mathrm{g}$ of DNA was digested overnight with $50 \mathrm{U}$ of restriction endonuclease. The fragments were separated on a $0.8 \%$ agarose gel and transferred onto nylon membranes (Duralon; Stratagene Ltd., Cambridge, U.K.) by capillary action $(22,23)$. The DNA was cross-linked to the membrane by exposure to ultraviolet radiation $(254 \mathrm{~nm})$ in a $1800 \mathrm{UV}$ Stratalinker (Stratagene Ltd., Cambridge, U.K.). Hybridization was carried out in $5 \times$ Denhardt's solution, $1 \%$ SDS, $5 \times$ SSPE, and $150 \mu \mathrm{g} / \mathrm{ml} \mathrm{Homomix} \mathrm{(24)} \mathrm{overnight}$ at $65^{\circ} \mathrm{C}$ for 24 hours. The DNA probes were radiolabeled with $\left[\alpha-{ }^{32} \mathrm{P}\right] \mathrm{dCTP}$ by random priming (25). The membranes were hybridized with two separate probes. The first was a $1.9-\mathrm{kb}$ probe containing FI coding cDNA (the cDNA was kindly provided by Dr. R.B. Sim, Oxford, UK [7]), the second was a 343-bp 5' probe that encompassed the first exon; it was obtained by PCR of genomic DNA using oligonucleotide primers Int 1 and Pro 1 . Int 1 bound to sequence in the first intron, and Pro 1 bound to sequence in the promoter (see Table II). The $5^{\prime}$ probe was generated by PCR to include sequences flanking the first exon owing to the exon's small size, $86 \mathrm{bp}$. The membranes were washed for $10 \mathrm{~min}$ in $2 \times \mathrm{SSC} / 0.1 \%$ SDS at room temperature, then at $65^{\circ} \mathrm{C}$ for 30 minutes, and then finally washed in $0.5 \times$ $\mathrm{SSC} / 0.1 \% \mathrm{SDS}$ at $65^{\circ} \mathrm{C}$ for $30 \mathrm{~min}$ (full-length cDNA probe), or in $1 \times$ SSC $/ 0.1 \%$ SDS ( $5^{\prime}$ probe). The membranes were then subject to autoradiography by exposing to Hyperfilm (Amersham International plc, Bucks, U.K.) at $-70^{\circ} \mathrm{C}$ for $2-7 \mathrm{~d}$.

Polymerase chain reaction $(P C R)$. The reaction was performed on $250 \mathrm{ng}$ of genomic DNA in $50 \mu \mathrm{l}$ containing $10 \mathrm{mM}$ Tris $\mathrm{pH} 8.3,50$ $\mathrm{mM} \mathrm{KCl}, 0.01 \%$ gelatin, $1.5 \mathrm{mM} \mathrm{MgCl}_{2}, 200 \mu \mathrm{M} \mathrm{dNTP}, 250 \mathrm{nM}$ of each primer and 1.25U of Taq DNA polymerase (Perkin Elmer Ltd., Beaconsfield, Bucks, U.K.). The PCR was run for 30 cycles as follows: $95^{\circ} \mathrm{C}$ for $1 \mathrm{~min} ; 50-55^{\circ} \mathrm{C}$ (depending on primer length) for 1 minute; $72^{\circ} \mathrm{C}$ for $1 \mathrm{~min}$. The sequence and position of the oligonucleotide primers used in genomic PCR are listed in Table II.
Reverse transcription and polymerase chain reaction (RT-PCR). Total RNA was extracted (26) from fibroblasts grown from the shave skin biopsies. $250 \mathrm{ng}$ of RNA was used as a substrate for first strand cDNA synthesis. This reaction was performed in $20 \mu \mathrm{l}$ using $200 \mathrm{U}$ of Superscript reverse transcriptase (GIBCO-BRL, Life Technologies, Paisley, Renfrewshire, Scotland) in $50 \mathrm{mM}$ Tris pH 8.3, $75 \mathrm{mM} \mathrm{KCl,} 3$ $\mathrm{mM} \mathrm{MgCl} 2,10 \mathrm{mM}$ dithiothreitol with $500 \mu \mathrm{M}$ dNTP. The priming oligonucleotide $(250 \mathrm{nM})$ was oligo $\mathrm{dT}_{12-18}$ (Pharmacia Biotech Ltd., Milton Keynes, U.K.). The reaction was incubated at $42^{\circ} \mathrm{C}$ for $45 \mathrm{~min}-$ utes, and then $99^{\circ} \mathrm{C}$ for $5 \mathrm{~min}$ to inactivate the enzyme. PCR was then performed on the whole RT reaction. The conditions used were as described above except that the reaction volume was $100 \mu$ l. The cDNA was amplified in 35 cycles as follows: $95^{\circ} \mathrm{C}$ for $1 \mathrm{~min} ; 52^{\circ} \mathrm{C}$ for 1 $\mathrm{min} ; 72^{\circ} \mathrm{C}$ for $1 \mathrm{~min}$. The RT-PCR products were cloned into the Bluescript (pBS) SK+ vector (Stratagene Ltd., Cambridge, U.K.) using standard techniques (22). This was facilitated by the inclusion of BamHI and EcoRI sites in the primers. The sequence and position of the oligonucleotide primers used in RT-PCR are shown in Table I. In each PCR and RT-PCR performed a negative control was included that contained no template.

DNA sequencing. Double-stranded dideoxy termination cyclesequencing (27) was carried out on RT-PCR fragments cloned in pBS. Genomic PCR products and the 3A-8B RT-PCR product were sequenced directly (28), and/or were phosphorylated and then cloned into $\mathrm{pBS}$ cut with SmaI and sequenced. The $\mathrm{mmol}^{\mathrm{TM}}$ cycle-sequencing system (Promega, Southampton, U.K.) was used according to manufacturer's instructions. The oligonucleotides used to prime the reactions (listed in Table II) were end-labeled with $\left[\gamma^{-32}\right.$ P]ATP (ICN Biomedicals Ltd., Thame, Oxfordshire, U.K.) using standard conditions (22). Internal primers that bound cDNA were used to sequence the RT-PCR clones. Internal primers were also used for direct sequencing of PCR products. The primers, T3 and T7, bind consensus sequences flanking the polylinker of pBS. The sequencing reaction products were analyzed by electrophoresis in denaturing polyacrylamide gels ( $6 \%$ polyacrylamide/7 $\mathrm{M}$ urea).

Shave skin biopsy. From a shave biopsy a sample of skin was taken (without the use of an alcohol swab) and immediately placed into RPMI 1640 medium (ICN Biomedicals Ltd., Thame, Oxfordshire, U.K.) containing $500 \mathrm{iu} / \mathrm{ml}$ penicillin, $500 \mu \mathrm{g} / \mathrm{ml}$ streptomycin, and 30 $\mu \mathrm{g} / \mathrm{ml}$ amphotericin B for $30 \mathrm{~min}$ in order to decontaminate the specimen. It was then removed from this medium and placed in RPMI with $20 \%$ FCS, $50 \mathrm{iu} / \mathrm{ml}$ penicillin, and $50 \mu \mathrm{g} / \mathrm{ml}$ streptomycin in which it was subsequently grown. The biopsy specimen was then cut into 5-10 pieces which were placed in $60-\mathrm{mm}$ diameter tissue culture dishes under coverslips. Once confluence was reached (3-5 wk) the fibroblasts were removed with trypsin/EDTA and grown in tissue culture flasks. The cells were harvested between the third and fourth passage.

Western blotting. Fibroblast lysates $\left(5 \times 10^{4}\right.$ cells/ $\mu$ l lysis buffer $)$ were prepared with the following lysis buffer: $6 \mathrm{mM}$ CHAPS, $50 \mathrm{mM}$ Tris $\mathrm{pH}$ 8.0, $150 \mathrm{mM} \mathrm{NaCl}, 5 \mathrm{mM}$ EDTA, $100 \mathrm{mM}$ iodoacetamide, $1 \%$ NP-40, $1 \mathrm{mM}$ PMSF. Protein electrophoresis was performed on SDS-PAGE gels (15\% polyacylamide) (29). After electrophoresis, the protein was transferred to a supported nitrocellulose membrane (Hybond C-Super, Amersham International plc, Bucks, U.K.) as described (30). The membrane to which the protein was bound was washed in a blocking solution for $24 \mathrm{~h}$ at $4^{\circ} \mathrm{C}$ before protein visualization. The blocking solution was $20 \mathrm{mM}$ Tris $\mathrm{pH} 7.6,137 \mathrm{mM} \mathrm{NaCl}$, $0.1 \%$ Tween- $20^{\mathrm{TM}}$ (polyoxyethylene-sorbitan monolaurate), $5 \%$ milk powder. The membrane was then incubated with the anti-factor I monoclonal antibody, MRC OX21 (31), in blocking solution for $1 \mathrm{~h}$ at $4^{\circ} \mathrm{C}$. The antibody concentration was $400 \mathrm{ng} / \mathrm{ml}$ and this was used at a dilution of 1:2,000. The membrane was washed in blocking solution and then incubated with a horseradish peroxidase-conjugated rabbit anti-mouse antibody (Sigma Chemical Company Ltd., Poole, Dorset, U.K.). The second antibody was also used at a dilution of 1:2,000. The membrane was then washed in blocking solution for $24 \mathrm{~h}$. Protein visualization was achieved using an Enhanced Chemiluminescence (ECL $\left.{ }^{\mathrm{TM}}\right)$ detection system (Amersham International plc, Bucks, U.K.) (32). 

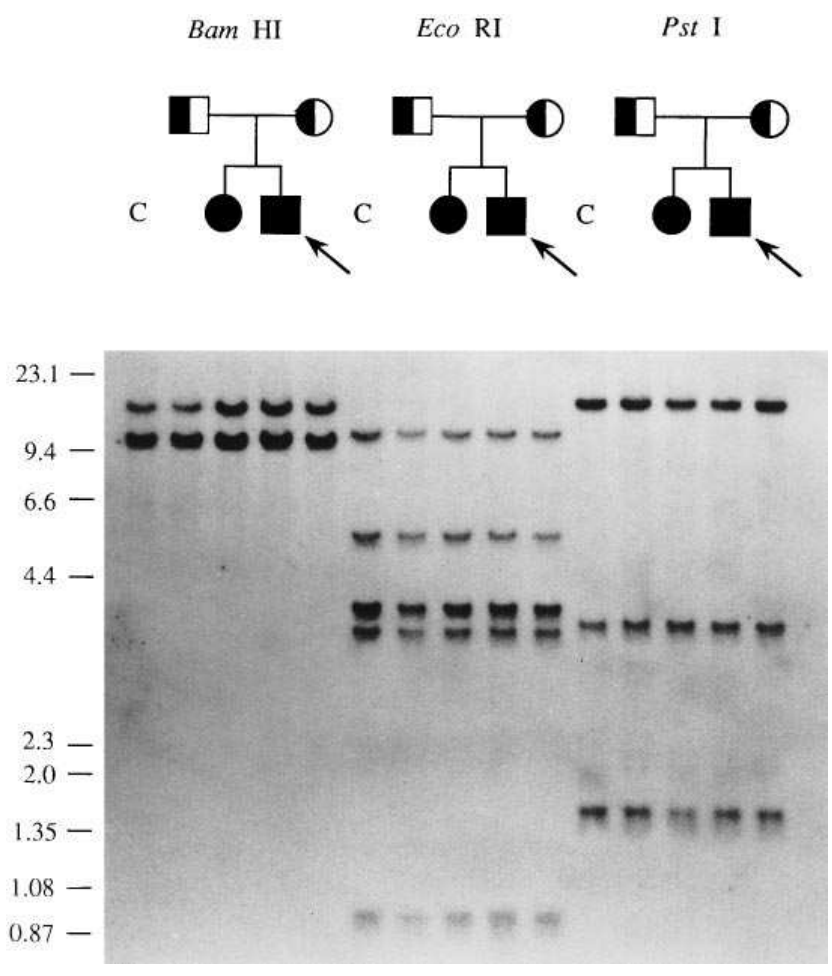

Figure 1. Analysis of genomic DNA from all four members of family 1 (designated in pedigree form above their respective lanes) and a normal control $(C)$. In each lane, $10 \mu \mathrm{g}$ of DNA was digested with BamHI, EcoRI, or PstI. On the left of the autoradiograph $\lambda /$ HindIII and $\phi X-174 /$ HaeIII size markers are given (in $\mathrm{kb}$ ). The probe used was FI coding cDNA $(1.9 \mathrm{~kb})$.

Metabolic labeling and immunoprecipitation of secreted proteins. Proteins synthesized by primary cultures of fibroblasts were radiolabeled as previously described (4). Briefly, confluent monolayers of fibroblasts or Hep G2 cells in $75-\mathrm{cm}^{2}$ flasks were stimulated with gamma-interferon $(500 \mathrm{U} / \mathrm{ml})$ for $24 \mathrm{~h}$. After washing twice with HBSS, cultures were incubated for $6 \mathrm{~h}$ with $6 \mathrm{ml}$ of DME/20\% FCS in the absence of glutamine, methionine or cystine (ICN Biomedicals
Ltd., Thame, Oxfordshire, U.K.) supplemented with $1 \mathrm{mCi}\left[{ }^{35} \mathrm{~S}\right] \mathrm{me}-$ thionine (Tran ${ }^{35} \mathrm{~S}$ Label; ICN Biomedicals Ltd., Thame, Oxfordshire, U.K.). After incubation, the media was removed and iodoacetamide was added to a final concentration of $2 \mathrm{mM}$ and the cells centrifuged at $500 \mathrm{~g}$ for $10 \mathrm{~min}$. The supernatant was removed and concentrated to $2 \mathrm{ml}$ in a Minicon column (Amicon Inc., Beverly, MA). The protein was separated from free radioactivity using a PD10 column (Pharmacia Biotech Ltd., Milton Keynes, U.K.) equilibrated with PBS containing $0.5 \mathrm{mM}$ EDTA. A single $3.5-\mathrm{ml}$ fraction of protein was collected at 2.5-6 ml elution volume. The $\mathrm{NaCl}$ concentration of the protein fraction was raised to $0.5 \mathrm{M}$. Human $\mathrm{IgG}$ was isolated on a Protein G column (Pierce \& Warriner, Rockford, IL) according to manufacturer's instructions and covalently bound to $\mathrm{CNBr}$-activated Sepharose 4B (Pharmacia Biotech Ltd., Milton Keynes, U.K.) (31). This IgG-Sepharose $(0.5 \mathrm{ml}$ packed volume $)$ was mixed with the sample and $100 \mu \mathrm{l}$ of normal human serum was added. After a 2-h incubation on a slow rotary stirrer at $2-6^{\circ} \mathrm{C}$, the resin was pelleted by centrifugation at $500 \mathrm{~g}$ for two min. The supernatant was transferred into a $10 \mathrm{ml}$ tube containing $30 \mu \mathrm{l}$ (packed volume) of MRC OX21Sepharose (prepared as described for IgG-Sepharose) and incubated for $2 \mathrm{~h}$ at $2-6^{\circ} \mathrm{C}$ on a slow rotary stirrer. Resin was pelleted and washed three times in $10 \mathrm{ml}$ of PBS containing $0.5 \mathrm{M} \mathrm{NaCl}$ and 0.5 mM EDTA followed by one wash in water. The resin pellet was mixed with $30 \mu \mathrm{l}$ of loading buffer, in the presence (reduced) or absence (nonreduced) of $0.7 \mathrm{M} \beta$-mercaptoethanol, boiled for $5 \mathrm{~min}$ and electrophoresed on an $8 \%$ polyacrylamide gel at $100 \mathrm{~V}$. The antifactor $\mathrm{H}$ monoclonal antibody, MRC OX23 coupled to Sepharose was used as a negative control.

\section{Results}

Southern blotting. The two families were first investigated by Southern blotting of genomic DNA. Neither family showed any evidence of gross rearrangement of gene structure using either the cDNA probe (Fig. 1) or the genomic DNA probe that included exon 1 (data not shown).

Family 1: investigation of $c D N A$. Since the Southern blot data indicated that in both pedigrees there was no large deletion or insertion within the FI gene, the cDNA from the homozygous FI deficient individuals was amplified by RT-PCR. Initially EBV-transformed B cells were used as the RNA substrate, but FI cDNA could not be reliably amplified from this source. Although fibroblasts have not been reported to synthe-

Table I. Location and Sequence of Oligonucleotide Primers Used in RT-PCR

\begin{tabular}{llc}
\hline \multicolumn{1}{c}{ Oligo } & \multicolumn{1}{c}{ Sequence } & Position \\
\hline $\begin{array}{l}\text { Primers used in RT-PCR } \\
\text { 1R }\end{array}$ & & $(58-77)$ \\
2H & TCTAGAATTCTGTGCTTCCACTTAAGG & $(736-753)$ \\
$3 \mathrm{R}$ & CATGGATCCCACAGGCTTTCATCTGAG & $(699-716)$ \\
$4 \mathrm{H}$ & GTAGAATTCGATGACTTCTTTCAGTGT & $(1742-1758)$ \\
$5 \mathrm{H}$ & AATCGGATCCAAGGCCTTCCTACATGG & $(1103-1119)$ \\
$6 \mathrm{R}$ & ATTAGGATCCTGATTCCACTGGCATCC & $(996-1014)$ \\
$7 \mathrm{H}$ & ACTGAATTCCTAAACTATCTTGTGGAG & $(1764-1780)$ \\
$3 \mathrm{~A}$ & TCTCGGATCCATACATTGTACTGAGA & $(380-399)$ \\
$8 \mathrm{~B}$ & $\underline{\text { GCATGGAAATACAGATTCAG }}$ & $(950-967)$ \\
& $\underline{\text { GCATCCATGTCAGCAGTC }}$ & \\
\hline
\end{tabular}

The oligonucleotide primers used in the RT-PCR that amplified the FI cDNA sequence are listed above. Their sequences are written (5' to $\left.3^{\prime}\right)$ followed by the nucleotide numbers in the cDNA (7) to which they correspond. The primers contain sequences at their $5^{\prime}$ ends that incorporate sites for the restriction enzymes BamHI and EcoRI. Oligonucleotides that are complementary to the negative strand contain an EcoRI site (designated R), those primers that are complementary to the positive strand include a BamHI (designated $\mathrm{H}$ ) restriction site. The region of the primer that binds to the cDNA template is shown underlined. 


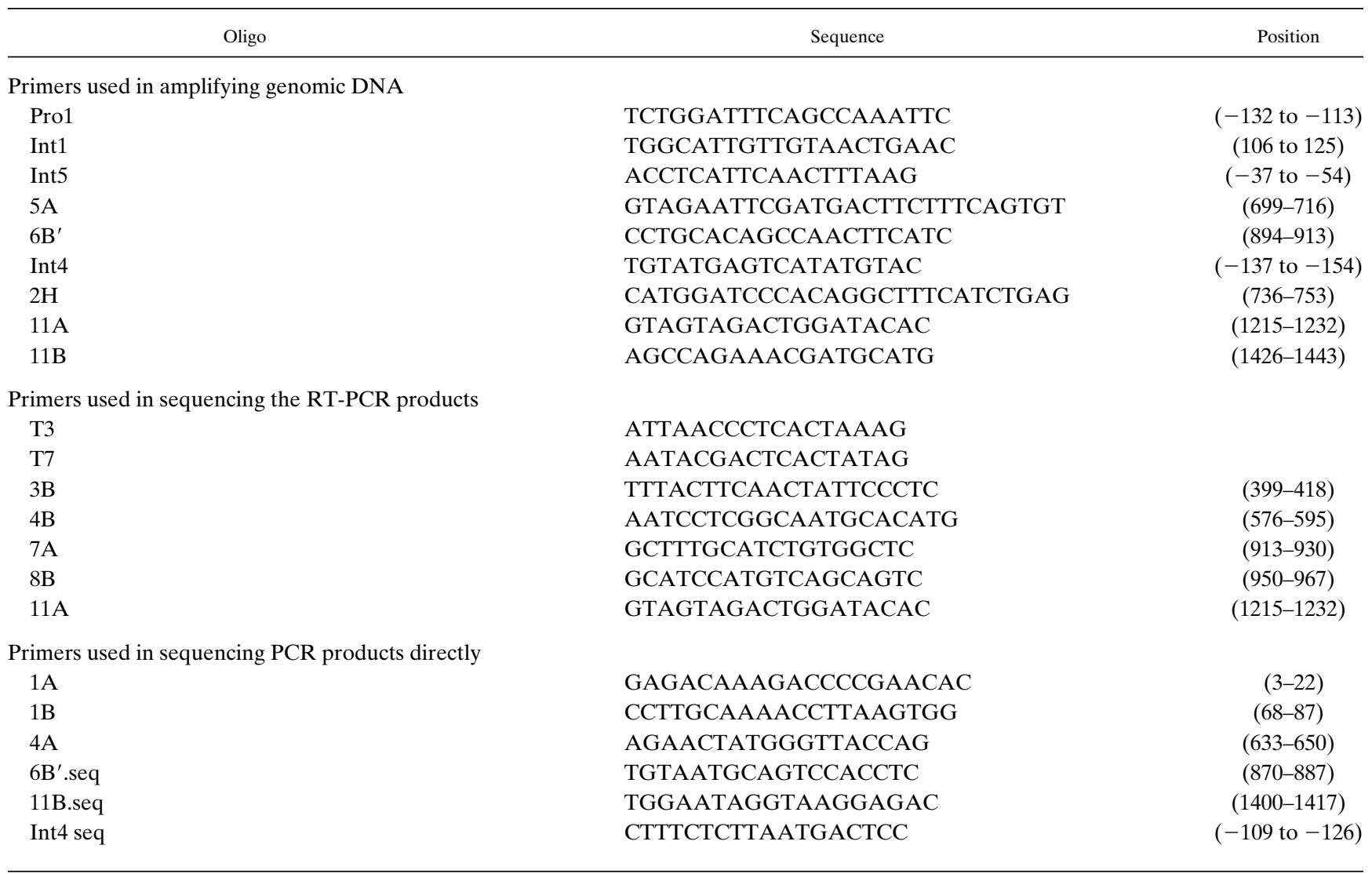

Oligonucleotides used in genomic DNA PCR and in cycle sequencing are listed. They are named as follows: the number refers to the exon to which the primer binds, the letter, A, shows that it is complementary to the negative strand, and the letter, B, that it is the positive strand to which the primer binds. Oligonucleotides termed, Int, bind to intronic sequence, their position is indicated by their distance from the nearest exon, negative numbers denote distance upstream (5'), and positive numbers distance downstream from the exon. Oligonucleotides T3 and T7 are complementary to unique sequences in the vector, $\mathrm{pBS}$.

size FI, they are known to secrete a large number of complement proteins, including those of the alternative pathway (33). When fibroblast RNA was used in RT-PCR, FI cDNA was amplified after 35 cycles of PCR. Shave skin biopsies were taken from the FI deficient individuals from both families to provide an RNA source. When the two siblings from family 1 were studied by RT-PCR, the cDNA (excluding the $3^{\prime}$ untranslated region) was amplified using oligonucleotide primers $1 \mathrm{R}$ and $2 \mathrm{H}$, and $3 \mathrm{R}$ and $4 \mathrm{H}$ (Table I). The RT-PCR generated normal-sized products of 711 and $1078 \mathrm{bp}$, respectively from each primer pair. These products were cloned into Bluescript and sequenced. Six clones containing each RT-PCR product were sequenced, the RT-PCR was repeated and a further six clones isolated and sequenced from the second reaction. Since the sequence of the first exon (which encodes the $5^{\prime}$ untranslated region and leader peptide) was not examined by RTPCR, the first exon was amplified from genomic DNA using primers Int 1 and Pro 1 . The product was then sequenced directly with primers, $1 \mathrm{~A}$ and $1 \mathrm{~B}$ (Table II). By this combined approach, only two sequence differences were found between the cDNA sequence and the promoter sequence of the FI deficient homozygotes in family 1 and the published FI cDNA sequence $(6,7)$ and promoter sequence (8). One difference was silent (see below) and the other difference was functional, an adenine to thymine transversion at nucleotide 1282 , nomencla- ture as in (7) (Fig. 2). This nucleotide is the second base in the histidine codon (CAT) and the effect of the transversion is to alter histidine-400 to a leucine residue. The mutation occurred in the eleventh exon of the FI gene within the serine proteinase region of the protein. The presence of this transversion was

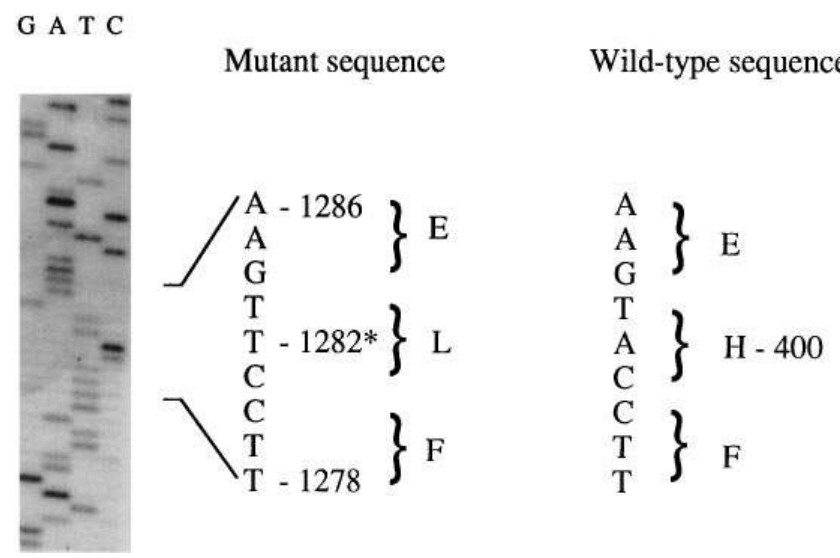

Figure 2. The sequence of the 3R/4H RT-PCR product cloned into pBS using oligo $11 \mathrm{~A}$ as the sequencing primer. The mutation at nucleotide 1282 is shown together with the resulting alteration in amino acid sequence compared with a normal control. 


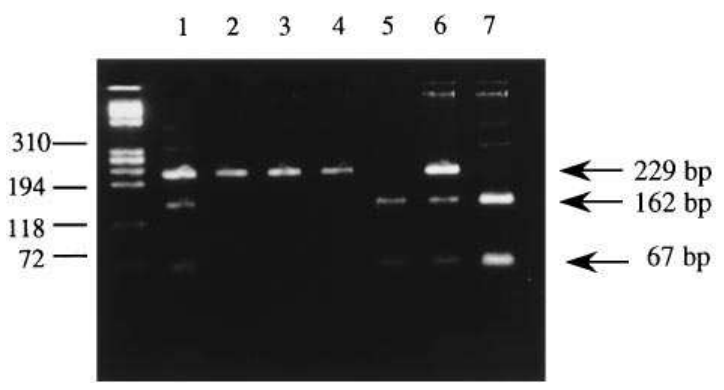

Figure 3. An ethidium bromide stained 3\% agarose gel with $\phi X-174 /$ HaeIII size markers (in bp) showing the genomic DNA PCR product obtained with oligos 11A and 11B (exon 11) that has been digested with NlaIII. The 229-bp PCR product is cut once by NlaIII in the normal control (lane 5). The product generated by the proband from family 1 (lane 2) and his sister (lane 3 ) are not cut owing to the 1282-T mutation. The proband from family 2 (lane 6 ) has a normal and mutant allele at position 1282 as do the parents from family 1 , the father (lane 1) and the mother (lane 4), though the digested products from the mother are not readily apparent in this photograph. The DNA of the mother from family 2 is cut by NlaIII (lane 7).

confirmed by two means. Firstly, the eleventh exon was amplified from genomic DNA by PCR using primers, 11A and 11B (see Table II). The PCR product was then sequenced directly with an internal primer, 11B.seq (see Table II). This indicated that the two FI deficient siblings in family 1 were both homozygous for the 1282-T mutation and both parents were heterozygous (data not shown). Secondly, the 1282-T mutation was found to remove an NlaIII recognition site in the wildtype sequence. Thus an NlaIII (New England Biolabs, CP Laboratories, Bishop's Stortford, Herts, U.K.) digest was carried out on the 11A-11B PCR product from all four members of family 1 and a normal control (Fig. 3). The findings were in agreement with the cDNA and genomic DNA sequence data.

To ascertain whether or not the mutation at nucleotide 1282 was a polymorphic variant, 100 normal individuals were

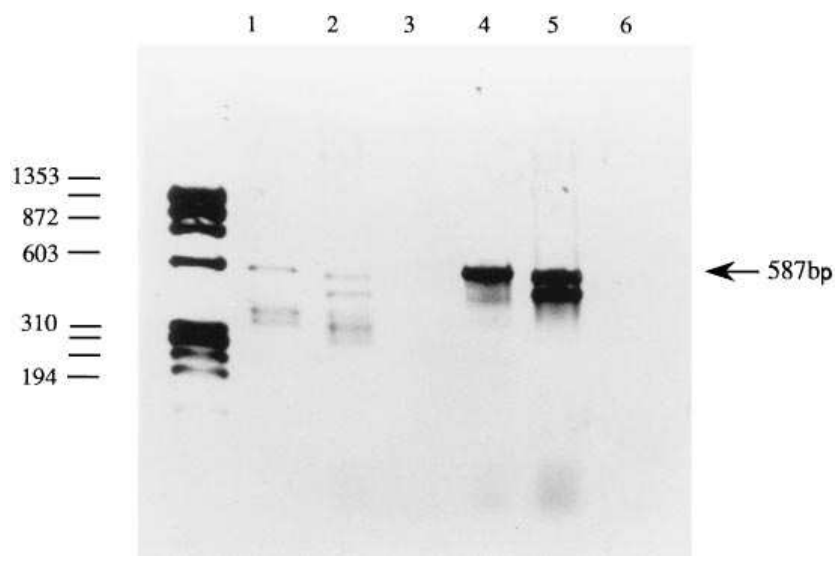

Figure 4. A $1.5 \%$ agarose gel (with $\phi \mathrm{X}-174 / \mathrm{HaeIII}$ size markers in bp) showing the RT-PCR products using oligos $3 \mathrm{~A}$ and $8 \mathrm{~B}$ that span the cDNA encoded by the fifth exon. The normal-sized product is 587 bp which is present in the normal control (lanes 1 and 4 ) and the proband of family 2 (lanes 2 and 5), negative control (lanes 3 and 6). The first three lanes were obtained after 35 cycles of PCR, and lanes 4- 6 after 40 cycles. A second additional product is seen in lanes 2 and 5 only. studied by PCR. Primers $11 \mathrm{~A}$ and $11 \mathrm{~B}$ were used and the product digested with NlaIII. All 100 PCR products were cut by NlaIII indicating that none had the transversion at 1282 (data not shown).

Family 2: investigation of $c D N A$. FI cDNA was amplified from the proband of family 2 . Three oligonucleotide primer pairs $1 \mathrm{R}$ and $2 \mathrm{H}, 3 \mathrm{R}$ and $5 \mathrm{H}$, and $6 \mathrm{R}$ and $7 \mathrm{H}$ were used (Table I). PCR products of 711, 439, and 802 bp were obtained respectively from each primer pair. There was no detectable difference in size between the products from normal fibroblasts and FI deficient fibroblasts (data not shown). As in family 1, 12 clones, six from two separate RT-PCRs, were isolated and sequenced. When 12 clones containing the PCR product of primers $6 \mathrm{R}$ and $7 \mathrm{H}$ (including nucleotide 1282) were sequenced it was found that six of them were normal and the other six had the same 1282-T mutation as identified in family 1 . It was confirmed that the proband was heterozygous for the 1282 transversion by an NlaIII digest on genomic PCR as shown in Fig. 3. The maternal FI deficient allele did not carry this mutation. No other functional changes were found when the remaining cDNA and promoter region were sequenced. However, the fact that half of the clones did not bear the 1282 mutation suggested that the defect on the maternal allele was compatible with RNA transcription, at least at the $3^{\prime}$ end. It was noted that RT-PCR primers, $2 \mathrm{H}$ and $3 \mathrm{R}$, both bound cDNA sequence that was encoded in the fifth exon of the FI gene. Thus if this exon was spliced out as a result of a splice-site mutation no PCR product would be generated from the allele with these two primers. Therefore RT-PCR was performed using primers $3 \mathrm{~A}$ and $8 \mathrm{~B}$ (see Table I) which lie outside the fifth exon sequence. A single product of $587 \mathrm{bp}$ was obtained from both normal and proband fibroblast RNA; a second smaller product ( $\sim 475 \mathrm{bp})$, in similar quantity to the larger one, was generated from the proband's RNA only (Fig. 4). The two PCR products from the proband were sequenced directly. The sequence of the smaller product revealed that the cDNA encoded by the fifth exon was completely absent (Fig. $5 a$ ). The sequence of the larger product contained ambiguities. The RT-PCR products were therefore cloned into pBS. Ten clones (five from one RT-PCR and five from a second reaction) containing each different-sized RT-PCR product were isolated and sequenced. All ten clones containing the smaller RT-PCR product had the fifth exon cDNA missing, with the fourth and sixth exons correctly spliced to one another (Fig. 5 b). The insert in these clones was therefore $473 \mathrm{bp}$ long. All of the ten clones containing the 587-bp product were the wild-type sequence (Fig. $5 \mathrm{c}$ ). To investigate the genomic lesion to account for this splicing defect the $3^{\prime}$ end of the fourth intron (using primers Int 4 and $2 \mathrm{H}$ ) and the entire fifth intron (using primers $3 \mathrm{R}$ and $6 \mathrm{~B}^{\prime}$ ) were amplified from genomic DNA and sequenced directly. The intron four PCR product was sequenced with primer Int 4 seq. (Table II). The 108 bp at the $3^{\prime}$ end of the fourth intron in the proband of family 2 and her mother were the same as a normal control. The complete fifth intron was directly sequenced with primer $6 \mathrm{~B}^{\prime}$.seq. The intron was the same as a normal control in the proband and her mother, however, the last base encoded by the fifth exon appeared to be heterozygous for a guanine to adenine transition in the proband and her mother. The genomic DNA PCR product from the proband, that spanned the fifth intron, was then cloned into $\mathrm{pBS}$. Ten clones were sequenced (five from one PCR, and five from a second PCR). Seven of these clones contained wild- 


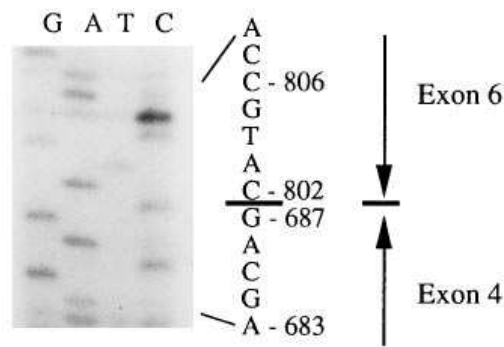

a
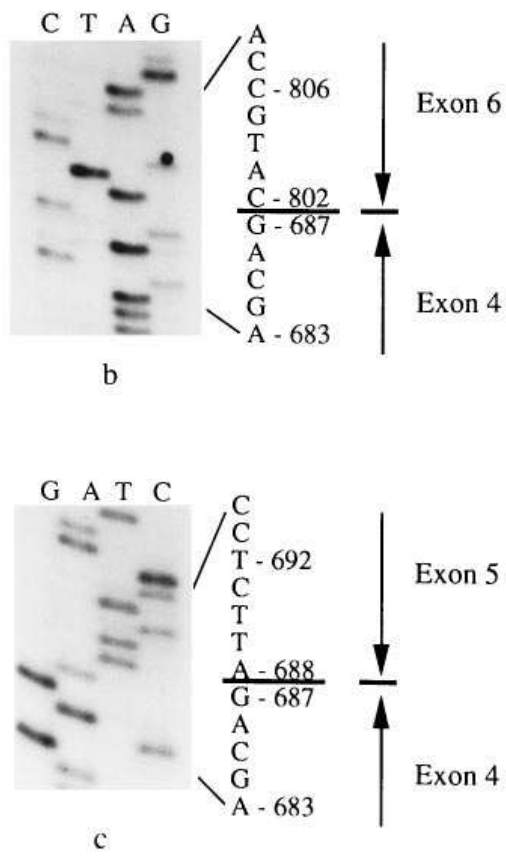

Figure 5. The sequence of the two RT-PCR

products generated from the proband of family 2 . In panel (a), the smaller product was sequenced directly with primer, 6B'.seq. In panel (b), the smaller RT-PCR product was cloned into $\mathrm{pBS}$ and sequenced with a vectorderived primer. The order of the sequence is reversed (CTAG) in

this panel. In $c$, the larger 587-bp RT-PCR product was cloned into $\mathrm{pBS}$ and sequenced with a vector-derived primer. The larger (587 bp) product is wildtype sequence, the other smaller product is normal until cDNA nucleotide 687 is reached, thereafter the sequence skips to nucleotide 802 . Nucleotide 687 is the last ( $\left.3^{\prime}\right)$ to be encoded by exon four and nucleotide 802 the first $\left(5^{\prime}\right)$ in exon six, the horizontal line demarcates cDNA derived from exon four (shown below) and exon six, or exon five (shown above).

type insert, whilst the other three had adenine at the $3^{\prime}$ end of exon five (Fig. 6). This site corresponds to position 801 in the cDNA and at the genomic level it constitutes part of the donor $\left(5^{\prime}\right)$ splice site recognition sequence of the fifth intron (34).

Analysis of the effect of the 1282-T mutation on FI protein expression. To investigate the effect of the 1282-T mutation fibroblast lysates were prepared. These were analyzed by western blotting using a sensitive detection system (enhanced chemiluminescence). A single signal of $M_{\mathrm{r}} 88,000$ was identified in the cell lysates $\left(10^{6}\right.$ fibroblasts) from a normal donor and from the FI deficient proband from family 1 (see Fig. 7). No signal was found in the supernatant of either fibroblast line (data not shown), presumably due to the low level of expression. However, FI was visualized in $4 \mu$ l of normal serum ( $\sim 140 \mathrm{ng}$ ) but not in the same volume of serum from the proband (FI could not be detected when $40 \mu$ l of serum was blotted). Since the patient is capable of synthesizing FI protein, detected intracellularly, one possible explanation for the absence of FI in the patient's serum would be a secretion defect. FI was undetectable in the supernatant from fibroblasts using western blotting. Therefore, a more sensitive technique was used to investigate the possibility of a secretory defect. After metabolic labeling of synthesized proteins with $\left[{ }^{35} \mathrm{~S}\right] \mathrm{me}-$ thionine, FI was immunoprecipitated and analyzed by polyacrylamide gel electrophoresis. Secreted FI was detected in

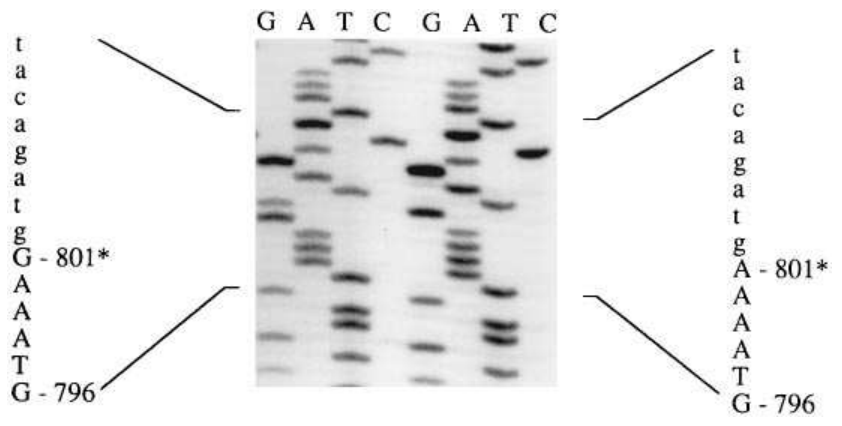

Figure 6. The sequence of genomic DNA that was amplified from the proband of family 2 with primers $6 \mathrm{~B}^{\prime}$ (binds in exon six) and $2 \mathrm{H}$ (binds in exon five). The PCR product was cloned into pBS. When ten clones were sequenced the inserts were identical except at the 3 '-most base encoded by the fifth exon (shown by an asterisk). Seven of the clones were wild-type (guanine), but three of them were adenine at this position. The numbers adjacent to the sequence corresponds to the cDNA position. Exonic sequence is denoted in upper case and intronic DNA is given in lower case. The proband was concluded to be heterozygous for adenine and guanine at the $3^{\prime}$ end of exon five, a region which forms part of the donor splice site consensus sequence of the fifth intron.

fibroblast culture supernatants from both the FI deficient proband and from a normal donor (Fig. 8). In four separate experiments the amount of immunoprecipitated FI produced by the patient and normal fibroblasts was always very similar and considerably less than the levels produced by HepG2. The FI was analyzed under reducing and non-reducing conditions and identical results were produced by both the normal and patient's fibroblasts (Fig. 8). Under non-reducing conditions, a single chain of $M_{\mathrm{r}} 88,000$ was identified, while under reducing conditions, two forms were secreted; a single band of $M_{\mathrm{r}}$ 88,000 , the pro FI molecule, and $10-20 \%$ as two bands of $M_{\mathrm{r}}$ 50,000 and 38,000 corresponding to the two chains of the mature FI. The presence of two secreted forms of FI under reduc-

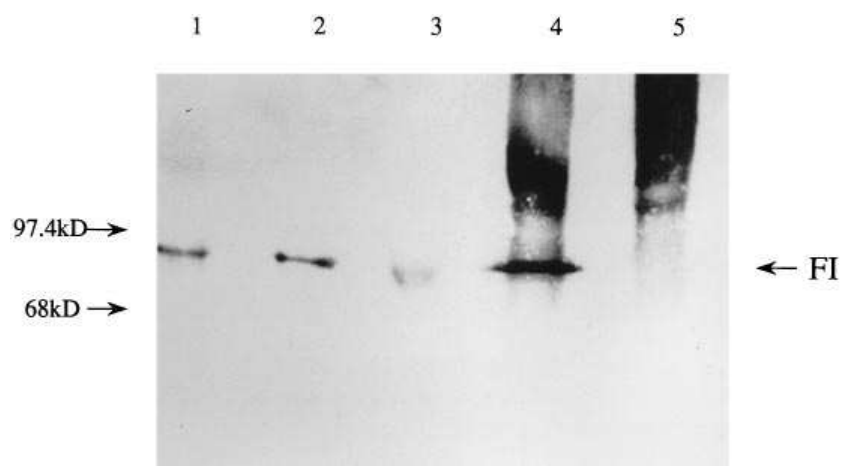

Figure 7. A western blot of fibroblast lysates and serum. Normal fibroblasts $\left(10^{6}\right.$ cells) were loaded in lane 1 and normal serum $(4 \mu \mathrm{l})$ in lane 4 . Fibroblasts from the proband of family $1\left(10^{6}\right.$ cells $)$ were loaded in lane 2 and his serum $(4 \mu \mathrm{l})$ in lane 5 . Lane 3 is a positive control, 100 ng of purified FI, prepared by affinity chromatography using the anti-FI monoclonal antibody, MRC OX21 (31). The blot was probed with the MRC OX21 antibody and horseradish peroxidase-conjugated rabbit anti-mouse antibody, the protein was detected by enhanced chemiluminescence. 


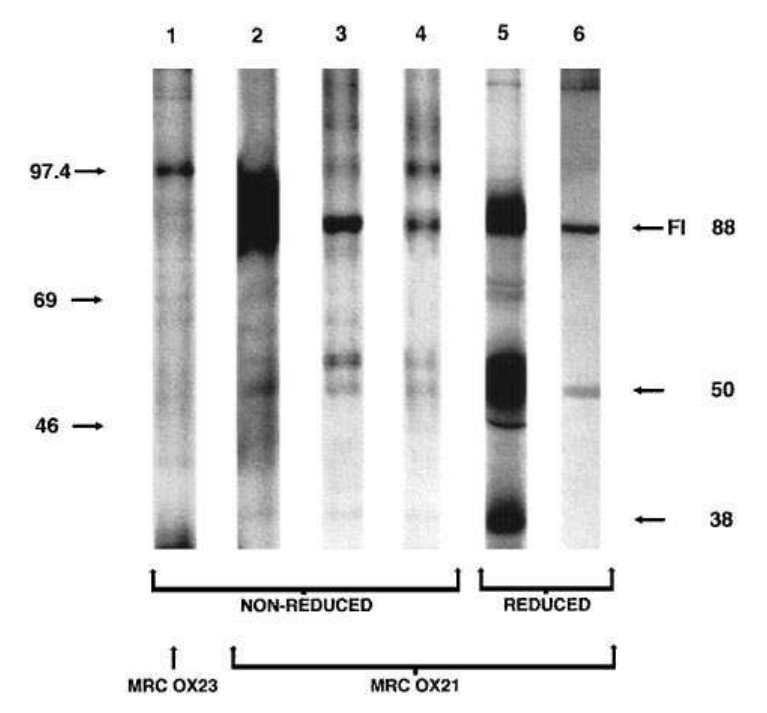

Figure 8. Autoradiograph following SDS 8\% polyacrylamide gel electrophoresis of immunoprecipitated $\left[{ }^{35} \mathrm{~S}\right]$ methionine-labeled FI from cell culture supernatants under non-reducing and reducing conditions. Samples were immunoprecipitated from the supernatant of HepG2 cells (lanes 1, 2, and 5), and from fibroblast cultures of the FI deficient patient (lanes 3 and 6 ) and of a healthy normal donor (lane 4). The immunobeads used for the immunoprecipitation are indicated below (MRC OX21 and MRC OX23, factor I and factor $\mathrm{H}$ specific monoclonal antibodies respectively). The position of the relative molecular mass standards $\left(M_{\mathrm{r}} \times 10^{-3}\right)$ is indicated on the left, while the FI chains are indicated on the right. The nonspecific bands appeared to a variable degree and are similar in $M_{\mathrm{r}}$ to nonspecific products identified previously in a number of hepatoma cell lines (2).

ing conditions has been reported previously for a number of hepatoma cell lines (2).

Identification of a silent mutation. The cDNA amplified from the probands of family 1 and family 2 were found to have a silent mutation at nucleotide 833 . Both probands had a guanine to adenine transition at this site which is in the serine-250 codon (TCG) (7). Serine-250 is encoded in the sixth exon (which encodes an LDLr module) of the FI gene. The genomic DNA was amplified by PCR using primers Int 5 and $6 \mathrm{~B}^{\prime}$ and then sequenced directly using primer $6 \mathrm{~B}^{\prime}$.seq. The nucleotide sequence indicated that the proband of family 1 is homozygous for 833-A as is the proband from family 2. Both mothers from the two families were 833-A/G heterozygotes, the father from family 1 was $833-A$ homozygous. Therefore both the 1282-T and 801-A mutations arose on the background of an 833-A allele, suggesting that the silent mutation may be common.

\section{Discussion}

The molecular basis of hereditary complement FI deficiency is described in two pedigrees. In the first pedigree, family 1 , there were two siblings both of whom had no detectable circulating FI, and no functional alternative pathway activity as assessed by haemolytic assay. The younger sibling, the proband, had a history of recurrent pyogenic infections and a single episode of $N$. meningitidis meningitis. His older (by five years) sister had no history of increased susceptibilty to infection. Analysis of the FI gene by Southern blotting gave no evidence of gross structural rearrangement and hence the affected siblings were investigated by sequencing their FI cDNA after RTPCR. The only functional change in sequence identified was a transversion (A to T) at nucleotide 1282. The effect of this mutation is to alter histidine-400 to leucine. It could be argued that the 1282-T mutation is not the basis for FI deficiency in family 1 but is simply a rare polymorphic variant. Two lines of evidence suggest that this is unlikely. Firstly, the transversion was not present in 100 normal DNA samples (200 alleles); and secondly, the mutation was identified on one of the FI alleles from the proband of family 2 . Both siblings from family 1 were homozygous for this mutation when genomic DNA was analyzed. The reasons for the disparity in clinical manifestations between the two siblings are not known. Clearly the fact that the molecular lesion is identical in both siblings indicates that the variation in phenotype is not related to genotype at the FI locus. Environmental factors may play a role, but since the onset of infection was at 18 mo in the proband, and the infections were recurrent involving different organ systems, an additional genetic component is implicated in disease susceptibility. Furthermore, there was no obvious environmental difference experienced by the two siblings. It may be speculated that since there is considerable redundancy in both the innate and adaptive immune systems, then variation at other loci could modify disease expression.

The 1282-T mutation occurs within the eleventh exon of the FI gene. Exons 10 through 13 encode the serine proteinase region of FI (8). The serine proteinases are a large group of biologically important enzymes that have been extensively studied. This category of enzymes includes, trypsin, other complement proteins, $\mathrm{C} 2, \mathrm{C} 1 \mathrm{r} / \mathrm{s}$, factor $\mathrm{D}$ and factor $\mathrm{B}$, and proteins of the fibrinolytic and coagulation cascades (35). When the serine proteinase amino acid sequences are aligned on the basis of crystallographic data and consensus secondary structure predictions (36), it is apparent that the histidine-400 residue (which is mutated to leucine by 1282-T) in FI is a semi-conserved histidine residue. Within the serine proteinase family much is known of the molecular mechanism of their catalytic activity, and amino acid structure that determines substrate specificity and susceptibility to specific inhibitors $(37,38)$. No function has been allocated to histidine-400 in FI, or the semiconserved histidine in the other serine proteinases, however, the presence of a semi-conserved residue in homologous proteins with differing specificities has been suggested to imply a structural rather than functional role for that residue (39).

The effect of the leucine substitution was investigated by western blotting of fibroblast lysates (Fig. 7). The technique allows the detection of less than $100 \mathrm{ng}$ of protein. No circulating FI could be detected in the serum of the proband. The presence of intracellular FI in the fibroblasts from the proband of family 1 raised the question as to whether the leucine substitution impedes normal FI secretion. Therefore we compared the supernatant of primary fibroblast cultures from the patient and a normal individual with that of a hepatoma cell line (Hep G2). After metabolic labeling, we were able to precipitate newly synthesized FI from the supernatant of the patient's cells (Fig. 8). While the amount of FI secreted was substantially less than produced by the reference hepatoma cell line, it was very similar to the level of FI secreted by the normal fibroblasts. Thus the patient's cells were capable, in vitro, of synthesizing and secreting a FI molecule, yet no FI was detectable in the patient's serum. There are two possible explanations for this apparent discrepancy. Firstly, the histidine to leucine mu- 
tation may affect the stability of the FI in serum. This would be very difficult to assess experimentally due to the very low levels of FI synthesized by the fibroblasts. Secondly, since the majority of serum FI is synthesized by the liver (2), hepatocytes may utilize different mechanisms from fibroblasts to process and secrete FI. Indeed, there is some evidence that this is the case since different hepatoma cell lines (Hep 3B, Hep G2, and NPLC-KC) process FI differently (2). Thus, the histidine to leucine mutation may prevent secretion of the FI by the liver while it remains unaffected in fibroblasts.

The sequence data from the proband of family 2 and her mother revealed that her paternally-derived FI allele had the same transversion as occurred in family 1 . The second family originate from northern England, whereas the first family are from western Scotland. There is no known connection between the two families. Initially no maternally derived mutation was evident. When different primers were used for RTPCR an alternatively spliced message, in similar amounts to normal-sized mRNA, was identified. The entire cDNA that encoded the fifth exon was absent from one allele in the proband. The acceptor $\left(3^{\prime}\right)$ splice site of the fourth intron and the entire fifth intron were amplified from genomic DNA and sequenced directly. The only mutation identified was a guanine to adenine transition at cDNA nucleotide 801, which is the $3^{\prime}$-most base encoded by the fifth exon (see Fig. 6). It therefore forms part of the donor $\left(5^{\prime}\right)$ splice site of the fifth intron. Both the mother and the proband were heterozygous for this mutation which was compatible with the data indicating that the 1282-T mutation on the other allele was not maternally derived.

The last base encoded by the exon at a donor splice site is not invariably guanine. In a recent large survey of 1446 splice sites (34), guanine was present at this position (denoted -1) in $78 \%$ of cases. Adenine was the next most common base with a frequency of $11 \%$. Thus a change from guanine to adenine might be expected to leave some residual splice site activity on the 801-A mutant allele found in family 2. In a review of 101 splice site mutations (40), mutations affecting positions -1 and -2 in the donor splice were less common than would be expected when compared with mutations affecting the invariant, intronic GT at positions +1 and +2 . This presumably reflects a detection bias since mutations outside of the invariant GT may permit some splicing activity. Three examples of a guanine to adenine transition at position -1 of a donor splice have been reported in detail in the literature (41-43). In each instance there was skipping of the upstream exon and in two cases there was a second transcript owing to residual splicing activity at the mutated donor splice site. One of these was in the COL1A2 gene and resulted in type VII Ehlers-Danlos syndrome (41). The cryptically spliced product was in-frame but the transition resulted in an amino acid substitution (isoleucine for methionine). The other mutation was in the $\beta$-hexosamidase A gene and caused infantile Tay-Sachs disease (42). The cryptically spliced transcript was also in-frame but there was no amino acid substitution. In the example studied in this paper only one transcript was detected from the 801-A mutant allele. One similar case has been reported (43). In this example the transition at -1 occurred in the porphobilinogen deaminase gene and resulted in acute intermittent porphyria.

The fifth exon of FI encodes the first of two adjacent LDLr modules in the heavy chain. The distance that separates the fifth from the sixth exon (also an LDLr module) is small, 142 bp (8). The fact that there are no other cryptic splice sites in the vicinity of the mutated donor site of the fifth intron is compatible with the small size of the fifth intron. In addition, if the scoring system (which reflects the similarity of any given splice site to the consensus sequence) devised by Shapiro and Senapathy (34) is applied to the wild-type sequence of the fifth exon's donor splice site, the score (using the primate frequency distribution) is $69 \%$. This score is low in comparison with the value of $82 \%$, which is the mean score observed in 62 wild-type donor splice sites that have been documented as being subject to mutation (40). Thus the donor splice site of the fifth intron of the FI gene is relatively weak and the transition at -1 (which reduces the Shapiro-Senapathy score to $56 \%$ ) is unlikely to allow any significant residual splicing activity. The fact that a donor splice site mutation causes skipping of the upstream exon during pre-mRNA processing has implications for the mechanism of RNA splicing. The skipping of the upstream exon can not be explained by independent recognition of the donor and acceptor splice sites. Such a model would generate a transcript containing the intronic sequence downstream of the mutated donor splice site. In recent models of spliceosome assembly (44) the recognition of the acceptor splice site by the spliceosome complex is followed by scanning downstream to the $3^{\prime}$ end of the adjacent exon. A mutation at this point (as in the 801-A mutation) would impede spliceosome assembly with loss of the complex at the $5^{\prime}$ and $3^{\prime}$ ends of the exon, thereby leading to complete excision of the exon and its adjacent introns during splicing. This is the situation identified in the 801-A mutant allele in family 2 .

The intron phase between the fifth and its neighboring exons is the same, phase I (8). Because of the conserved intron phase it is possible that the shortened mRNA is translated and processed to a smaller product of 523 (normal 561) amino acids. This possibility was not investigated.

A silent mutation (guanine to adenine) at nucleotide 833 was identified. The transition at this position was present on both of the FI deficient mutant alleles described in this paper. In addition, the father from family 1 was homozygous 833-A, which suggests that the silent mutation is relatively common.

In conclusion, two different molecular lesions that give rise to FI deficiency have been identified. In one pedigree two siblings with FI deficiency (although one is asymptomatic) have the same missense mutation within the serine proteinase region of FI. In the resulting protein leucine replaces histidine400 , the latter is a semi-conserved histidine within the serine proteinase family. No function has been ascribed to this histidine residue. It was demonstrated that fibroblasts from the patient can synthesize and secrete the mutant FI protein in vitro but no FI was detectable in serum derived from the patient. The mechanism by which the histidine- 400 mutation causes FI deficiency has not been determined. In the second pedigree, the proband was found to be a compound heterozygote. One allele carried the same mutation as identified in family 1 , the second allele had an unusual donor splice site mutation that caused skipping of the sequence encoded by the fifth exon from its processed transcript. This is the first description of the genetic defect in FI deficiency.

\section{Acknowledgments}

We gratefully acknowledge the assistance and co-operation of the members of the two families that were studied in this paper. Family 2 
was originally reported by Dr. R.A. Thompson, Regional Immunology Laboratory, East Birmingham Hospital, Birmingham, and Professor P.J. Lachmann, MRC Molecular Immunopathology Unit, Hills Road, Cambridge. We acknowledge Ms. Jenny Morris, Dermatology Unit, RPMS for advice concerning the initiation of fibroblast cell lines and Dr. P.K. Potter, Rheumatology Unit, RPMS for advice concerning Western blotting. We thank Dr. S.J. Perkins, Biochemistry Department, Royal Free Hospital Medical School, Rowland Hill St., London for helpful discussion concerning the structure of factor I and use of molecular graphics equipment. Dr. R.B. Sim, MRC Immunochemistry Unit, Oxford, kindly provided the factor I cloned cDNA, the anti-factor I monoclonal antibody, MRC OX21, the anti-factor $\mathrm{H}$ monoclonal antibody, MRC OX 23, and the purified factor I protein used in Western blotting.

Dr. T.J. Vyse was supported by an Arthritis and Rheumatism Council (ARC) Research Fellowship and Dr. K.A. Davies is an ARC Senior Research Fellow.

\section{References}

1. Vyse, T.J., P.J. Späth, K.A. Davies, B.J. Morley, P. Philippe, P. Athanassiou, C.M. Giles, and M.J. Walport. 1994. Hereditary complement factor I deficiency. Quart. J. Med. 87:385-402.

2. Goldberger, G., M.A. Arnaout, D. Aden, R. Kay, M. Rits, and H.R. Colten. 1984. Biosynthesis and postsynthetic processing of human $\mathrm{C} 3 \mathrm{~b} / \mathrm{C} 4 \mathrm{~b}$ inactivator (factor I) in three hepatoma cell lines. J. Biol. Chem. 259:6492-6497.

3. Whaley, K. 1980. Biosynthesis of the complement components and the regulatory proteins of the alternative complement pathway by the human peripheral blood monocytes. J. Exp. Med. 151:501-516.

4. Julen, N., H. Dauchel, C. Lemercier, R.B. Sim, M. Fontaine, and J. Ripoche. 1992. In vitro biosynthesis of complement factor I by human endothelial cells. Eur. J. Immunol. 22:213-217.

5. Vetvicka, V., W. Reed, M.L. Hoover, and G.D. Ross. 1993. Complement factors $\mathrm{H}$ and I synthesised by B cell lines function to generate a growth factor activity from C3. J. Immunol. 150:4052-4060.

6. Goldberger, G., G.A.P. Bruns, M. Rits, M.D. Edge, and D.J. Kwiatkowski. 1987. Human complement factor I: analysis of cDNA-derived primary structure and assignment of its gene to chromosome 4. J. Biol. Chem. 262: 10065-10071.

7. Catterall, C.F., A. Lyons, R.B. Sim, A.J. Day, and T.J.R. Harris. 1987. Characterization of primary amino acid sequence of human complement control protein factor I from an analysis of cDNA clones. Biochem. J. 242:849-856.

8. Vyse, T.J., G.P. Bates, M.J. Walport, and B.J. Morley. 1994. The organisation of the human complement factor I gene: a member of the serine protease gene family. Genomics. 24:90-98.

9. Shiang, R., J.C. Murray, C.C. Morton, K.H. Buetow, J.J. Wasmuth, A.H. Olney, W.G. Sanger, and G. Goldberger. 1989. Mapping of the human complement factor I gene to 4q25. Genomics. 4:82-86.

10. Nagasawa, S., and R.M. Stroud. 1977. Mechanism of action of the C3b inactivator: Requirement for a high molecular weight cofactor (C3b-C4bINA cofactor) and production of a new $\mathrm{C} 3 \mathrm{~b}$ derivative $\left(\mathrm{C}^{3} \mathrm{~b}^{\prime}\right)$. Immunochemistry. 14:749-756.

11. Pangburn, M.K., R.D. Schreiber, and H.J. Müller-Eberhard. 1977. Human complement $\mathrm{C} 3 \mathrm{~b}$ inactivator: isolation, characterization, and demonstration of an absolute requirement for the serum protein b1H for cleavage of $\mathrm{C} 3 \mathrm{~b}$ and C4b in solution. J. Exp. Med. 146:257-270.

12. Alper, C.A., N. Abramson, J.B. Johnston, J.H. Jandl, and F.S. Rosen. 1970. Increased susceptibility to infection associated with abnormalities of complement-mediated functions and of the third component of complement (C3). N. Engl. J. Med. 282:349-352

13. Abramson, N., C.A. Alper, P.J. Lachmann, F.S. Rosen, and J.H. Jandl. 1971. Deficiency of C3 inactivator in man. J. Immunol. 107:19-27.

14. Alper, C.A., F.S. Rosen, and P.J. Lachmann. 1972. Inactivator of the third component of complement as an inhibitor in the properdin pathway. Proc. Natl. Acad. Sci. USA. 69:2910-2913.

15. Ziegler, J.B., C.A. Alper, R.S. Rosen, P.J. Lachmann, and L. Sherington. 1975. Restoration by purified C3b inactivator of complement-mediated function in vivo in a patient with C3b inactivator deficiency. J. Clin. Invest. 55: $668-672$

16. Lachmann, P.J., and P. Nicol. 1973. Reaction mechanism of the alternative pathway of complement fixation. Lancet. 1:465-467.

17. Møller Rasmussen, J., B. Teisner, H.H. Jepsen, S.E. Svehag, F. Knudsen, H. Kirstein, and M. Buhl. 1988. Three cases of factor I deficiency: the effect of treatment with plasma. Clin. Exp. Immunol. 74:131-136.
18. Solal-Celigny, P., M. Laviolette, J. Hebert, P.C. Atkins, M. Sirois, G. Brun, G. Lehner-Netsch, and J.M. Delâge. 1982. C3b inactivator deficiency with immune complex manifestations. Clin. Exp. Immunol. 47:197-205.

19. Maillet, F., L. Weiss, J. Chibani, and M. Kazatchkine. 1990. Déficit en facteur I, une proteine regulatrice du complement. Nouv. Presse. Med. 19:762. (letter).

20. Harrison, R.A., and P.J. Lachmann. 1986. Complement technology. In Handbook of Experimental Immunology, Volume 1, Immunochemistry. D.M Weir, L.A. Herzenberg, C. Blackwell, and Leonore A. Herzenberg, editors. Blackwell Scientific Publications, Oxford, 39.1-39.49.

21. Thompson, R.A., and P.J. Lachmann. 1977. A second case of human C3b inhibitor (KAF) deficiency. Clin. Exp. Immunol. 27:23-29.

22. Sambrook, J., E.F. Fritsch, and T. Maniatis. 1989. Molecular Cloning: A Laboratory Manual. Cold Spring Harbor Laboratory Press., Cold Spring Harbor, New York.

23. Southern, E. 1975. Detection of specific sequences among DNA fragments separated by gel electrophoresis. J. Mol. Biol. 98:503-517.

24. Jay, E., R. Bambura, R. Paomanabhan, and W.U. Ray. 1974. DNA sequence analysis: a general simple and rapid method for sequencing large oligodeoxyribonucleotide fragments by mapping. Nucleic Acids Res. 1:331-353.

25. Feinberg, A.P., and B. Vogelstein. 1983. A technique for radiolabeling DNA restriction endonuclease fragments to high specific activity. Anal. Biochem. 132:6-13.

26. Chomczynski, P., and N. Sacchi. 1987. Single-step method of RNA isolation by acid guanidium thiocyanate-phenol-chloroform extraction. Anal. Biochem. 162:156-159.

27. Innis, M.A., K.B. Myambo, D.H. Gelfand, and M.A.D. Brow. 1988 DNA sequencing with Thermus aquaticus DNA polymerase and direct sequencing of polymerase chain reaction-amplified DNA. Proc. Natl. Acad. Sci. USA. 85:9436-9440.

28. Engelke, D.R., P.A. Hoener, and F.S. Collins. 1988. Direct sequencing of enzymically amplified human DNA. Proc. Natl. Acad. Sci. USA. 85:544-548.

29. Laemmli, U.K. 1970. Cleavage of structural proteins during the assembly of the head of bacteriophage T4. Nature (Lond.). 277:680-685.

30. Towbin, H., T. Staehelin, and J. Gordon. 1979. Electrophoretic transfer of proteins from polyacrylamide gels to nitrocellulose sheets: procedure and source applications. Proc. Natl. Acad. Sci. USA. 76:4350-4354.

31. Sim, R.B., A.J. Day, B.E. Moffatt, and M. Fontaine. 1993. Complement factor I and cofactors in control of complement system convertase enzymes. Methods Enzymol. 223:13-35.

32. Whitehead, T.P., L.J. Kricka, T.J.N. Carter, and G.H.G. Thorpe. 1979. Analytical chemiluminescence: its potential in the clinical laboratory. Clin. Chem. 25:1531-1546.

33. Katz, Y., and R.C. Strunk. 1988. Synthesis and regulation of complement protein factor H in human skin fibroblasts. J. Immunol. 141:559-563.

34. Shapiro, M.B., and P. Senapathy. 1987. RNA splice junctions of different classes of eukaryotes: sequence statistics and functional implications in gene expression. Nucleic Acids Res. 15:7155-7174.

35. Neurath, H. 1985. Proteolytic enzymes, past and present. Fed. Proc. 44 2907-2913.

36. Perkins, S.J., and K.F. Smith. 1993. Identity of the putative serine-proteinase fold in proteins of the complement system with nine relevant crystal structures. Biochem. J. 295:109-114.

37. Kraut, J. 1977. Serine proteases: structure and mechanism of catalysis. Ann. Rev. Biochem. 46:331-358.

38. Bode, W., E. Meyer, and J.C. Powers. 1989. Human leucocyte and porcine pancreatic elastase: X-ray crystal structures, mechanism, substrate specificity, and mechanism-based inhibitors. Biochemistry. 28:1951-1963.

39. Patthy, L. 1993. Modular design of proteases of coagulation, fibrinolysis, and complement activation: Implications for protein engineering and structurefunction studies. Methods Enzymol. 222:10-22.

40. Krawczak, M. , J. Reiss, and D.N. Cooper. 1992. The mutational spectrum of single base-pair substitutions in mRNA splice junctions of human genes: causes and consequences. Hum. Genet. 90:41-54.

41. Weil, D., M. D'Alessio, F. Ramirez, B. Steinmann, M.K. Wirtz, R.W. Glanville, and D.W. Hollister. 1989. Temperature-dependent expression of a collagen splicing defect in the fibroblasts of a patient with Ehlers-Danlos syndrome type VII. J. Biol. Chem. 264:16804-16809.

42. Akli, S., J. Chelly, C. Mezard, S. Gandy, A. Kahn, and L. Poenaru. 1990. A "G" to " $A$ " mutation at position -1 of a 5 ' splice site in a late infantile form of Tay-Sachs disease. J. Biol. Chem. 265:7324-7330.

43. Grandchamp, B., C. Picat, F. de Rooji, C. Beaumont, P. Wilson, J.C. Daybach, and Y. Nordmann. 1989. A point mutation G-A in exon 12 of the porphobilinogen deaminase gene results in an exon skipping and is responsible for acute intermittent porphyria. Nucleic Acids Res. 17:6637-6649.

44. Robberson, B.L., J.G. Cote, and S.M. Berget. 1990. Exon definition may facilitate splice site selection in RNAs with multiple exons. Mol. Cell. Biol. 10: 84-94. 